\title{
The Lighter Side
}

Send contributions to The Lighter Side to the editor (address on the inside front cover).

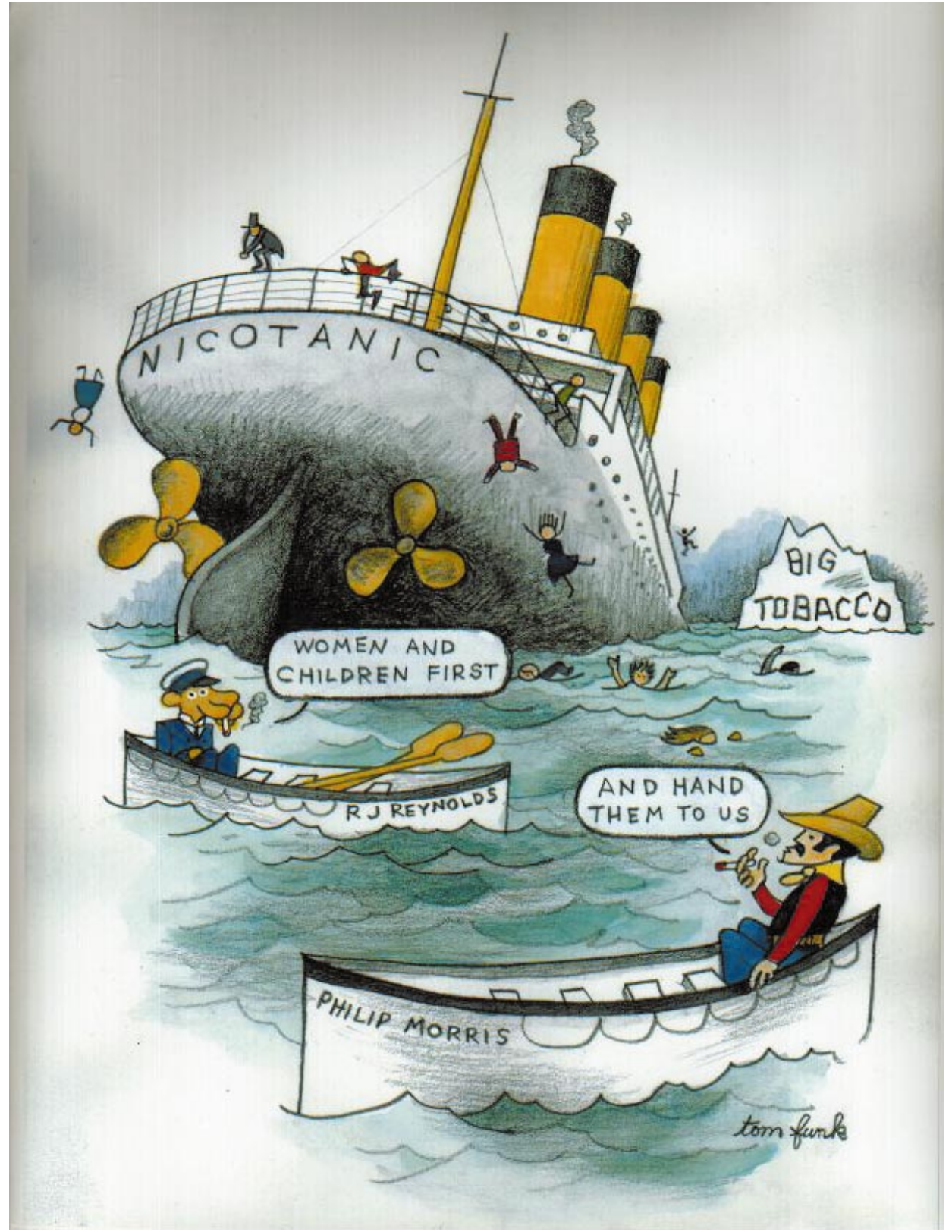

Drawing by Tom Funk, an artist who formerly worked for The New Yorker magazine. 